\title{
C-reactive protein and body composition in a representative sample of young adults
}

\author{
L. K. Forsythe, M. B. E. Livingstone, M. S. Barnes, G. Horigan and J. M. W. Wallace \\ Northern Ireland Centre for Food and Health, University of Ulster, Coleraine BT52 1SA, UK
}

\begin{abstract}
Adipose tissue secretes a number of proteins and other inflammatory molecules, termed adipokines ${ }^{(1)}$. Circulating levels of these adipokines become dysregulated with increased adiposity, providing a mechanism linking obesity to its co-morbidities ${ }^{(2)}$. However, to date most studies have focused on obese or morbidly-obese populations. The aim of the present study was to investigate the relationship between body composition and C-reactive protein (CRP) as a marker of inflammation and an independent risk factor for vascular disease $^{(3)}$ in a representative sample of young adults. Apparently-healthy men and women aged 20-40 years (n 119; fifty-eight males and sixty-one females), recruited from the local population, provided a single fasting blood sample that was used to measure CRP concentration. Anthropometric measurements included height, weight and waist circumference. Fat and fat-free mass were measured by airdisplacement plethysmography (BODPOD ${ }^{\circledR}$; Life Measurement Inc., Concord, CA, USA) and adjusted for height to give fat mass index and fat-free mass index respectively. Data for men and women were analysed separately. Differences in CRP between the age-groups approached significance for females $(P=0.05)$ and were significant for males $(P=0.04)$, therefore age-group-specific analysis was also performed.
\end{abstract}

\begin{tabular}{|c|c|c|c|c|c|c|}
\hline & \multicolumn{3}{|c|}{ Females aged $\leq 30$ years $(n$ 31) } & \multicolumn{3}{|c|}{ Females aged $>30$ years $(n 30)$} \\
\hline & OR & $95 \% \mathrm{CI}$ & $P^{*}$ & OR & $95 \% \mathrm{CI}$ & $P^{*}$ \\
\hline Weight (kg) & 1.05 & $0.99,1.12$ & 0.09 & 1.00 & $0.95,1.06$ & 0.97 \\
\hline $\operatorname{BMI}\left(\mathrm{kg} / \mathrm{m}^{2}\right)$ & 1.18 & $0.97,1.42$ & 0.09 & 1.05 & $0.90,1.23$ & 0.52 \\
\hline Waist circumference $(\mathrm{cm})$ & 1.05 & $0.97,1.14$ & 0.22 & 1.03 & $0.96,1.10$ & 0.40 \\
\hline Fat mass (kg) & 1.10 & $1.01,1.21$ & 0.04 & 1.01 & $0.95,1.09$ & 0.70 \\
\hline Fat mass $(\%)$ & 1.11 & $0.99,1.23$ & 0.06 & 1.03 & $0.94,1.12$ & 0.56 \\
\hline Fat mass index $\left(\mathrm{kg} / \mathrm{m}^{2}\right)$ & 1.32 & $1.02,1.70$ & 0.03 & 1.06 & $0.88,1.29$ & 0.53 \\
\hline Fat-free mass $(\mathrm{kg})$ & 1.10 & $0.94,1.28$ & 0.24 & 0.95 & $0.82,1.09$ & 0.44 \\
\hline Fat-free mass index $\left(\mathrm{kg} / \mathrm{m}^{2}\right)$ & 1.07 & $0.62,1.84$ & 0.82 & 1.10 & $0.67,1.80$ & 0.71 \\
\hline Fat: fat-free mass $(\%)$ & 1.05 & $1.00,1.09$ & 0.04 & 1.01 & $0.98,1.05$ & 0.51 \\
\hline
\end{tabular}

* Significant predictors of CRP $(P<0.05)$ were determined by logistic regression analysis with age included as a covariate.

For women body composition was not significantly different between those aged $\leq 30$ years and those aged $>30$ years. Logistic regression analyses, including age, showed that fat mass, fat mass index and fat:fat-free mass (\%) were significant predictors of CRP in younger women (aged $\leq 30$ years). The OR showed that for each unit increase in fat mass, fat mass index and fat:fat-free mass ( $\%)$ the risk of having a higher CRP (defined as above the median; $>1.2 \mathrm{mg} / \mathrm{l}$ ) increased by $10 \%, 32 \%$ and $5 \%$ respectively. Body composition did not predict CRP for women aged $>30$ years or for men (data not shown).

In conclusion, for healthy young women (aged $\leq 30$ years) fat mass, particularly fat mass adjusted for height, predicts circulating concentrations of the inflammatory marker CRP. These results also highlight the importance of accurately measuring body composition and appropriately adjusting for body size when examining the associations between inflammatory markers and body composition.

We would like to acknowledge the Department of Education \& Learning and the Food Standards Agency for their support.

1. Trayhurn P \& Wood IS (2004) Br J Nutr 92, 347-355.

2. Fantuzzi G (2005) J Allergy Clin Immunol 115, 911-919.

3. Ridker PM, Buring JE, Cook NR \& Raifai N (2003) Circulation 107, 391-397. 